\title{
GLUT1 and GLUT8 in endometrium and endometrial adenocarcinoma
}

\author{
Noah A Goldman ${ }^{1,2, *}$, Ellen B Katz ${ }^{2}$, Alan S Glenn ${ }^{2}$, Richard H Weldon ${ }^{2}$, Joan G Jones ${ }^{3, \dagger}$, \\ Uticia Lynch $^{1,2}$, Melissa J Fezzari ${ }^{4}$, Carolyn D Runowicz ${ }^{1, \ddagger}$, Gary L Goldberg ${ }^{1}$ \\ and Maureen J Charron ${ }^{1,2}$
}

${ }^{1}$ Division of Gynecologic Oncology, Departments of Obstetrics \& Gynecology, and Women's Health, Albert Einstein College of Medicine and Montefiore Medical Center, Albert Einstein Comprehensive Cancer Center, Bronx, NY, USA; ${ }^{2}$ Department of Biochemistry, Albert Einstein College of Medicine and Montefiore Medical Center, Albert Einstein Comprehensive Cancer Center, Bronx, NY, USA; ${ }^{3}$ Department of Pathology, Albert Einstein College of Medicine and Montefiore Medical Center, Albert Einstein Comprehensive Cancer Center, Bronx, NY, USA and ${ }^{4}$ Department of Epidemiology and Biostatistics, Albert Einstein College of Medicine and Montefiore Medical Center, Albert Einstein Comprehensive Cancer Center, Bronx, NY, USA

\begin{abstract}
Glucose is provided to cells by a family of glucose transport facilitators known as GLUTs. These transporters are expressed in a tissue specific manner and are overexpressed in many primary tumors of these tissues. Regulation of glucose transport facilitator expression has been demonstrated in endometrial tissue and endometrial adenocarcinoma. The following experiments were conducted to quantify and localize the expression of GLUT1 and GLUT8 in benign endometrium and compare this expression to endometrial cancer. Endometrial tissue samples were obtained from random hysterectomy specimens of patients with benign indications for surgery and endometrial cancer. Immunoblot and immunolocatization studies were performed using GLUT1 and GLUT8 specific antisera. Endometrial samples from 65 women who had undergone hysterectomy were examined ( $n=38$ benign, $n=27$ malignant). A 44 and a $35.4 \mathrm{kDa}$ immunoreacive species was demonstrated in endometrium and endometrial cancer for GLUT1 and GLUT8, respectively. Upregulation of GLUT1 expression was demonstrated with increasing grade of tumors $(P<0.002)$. GLUT8 expression was increased in all tumor subtypes compared to atrophic endometrium $(P<0.001)$. Apical localization by GLUT1 and GLUT8 was demonstrated in endometrial glands. GLUT1 and GLUT8 demonstrated diffuse intracellular localization in the cancer subtypes. GLUT1 and GLUT8 are expressed in both human endometrium and endometrial cancer. There appears to be a step-wise progression in GLUT1 and GLUT8 expression as tumor histopathology worsens. GLUT1 and GLUT8 may be important markers in tumor differentiation, as well as providing energy to rapidly dividing tumor cells.
\end{abstract}

Modern Pathology (2006) 19, 1429-1436. doi:10.1038/modpathol.3800656; published online 4 August 2006

Keywords: glucose transport facilitators; uterine cancer; immunofluorescence

Glucose uptake, glycolysis, and energy production are increased in tumor cells. In 1930, Warburg

Correspondence: Dr MJ Charron, PhD, Department of Biochemistry, Albert Einstein College of Medicine, 1300 Morris Park Avenue, F312, Bronx, NY 10461, USA.

E-mail: charron@aecom.yu.edu

${ }^{*}$ Current address: Department of Obstetrics and Gynecology, New York University Clinical Cancer Institute, 160 East 34 St., New York, NY 10016, USA

†Current address: Departments of Pathology and Laboratory Medicine, Weill Medical College, New York Presbyterian Hospital, 525 East 68 St., Starr 1002, New York, NY 10021, USA

${ }^{\ddagger}$ Current address: Department of Obstetrics and Gynecology, University of Connecticut Health Center, Neag Comprehensive Cancer Program, 263 Farmington Avenue, Farmington, CT 060301614, USA

Received 6 February 2006; revised 6 June 2006; accepted 7 June 2006; published online 4 August 2006 described the high rates of glycolysis in tumor cells and noted the lack of inhibition of glycolysis by oxygen. ${ }^{1}$ Others have confirmed Warburg's observations. ${ }^{2,3}$ To provide the substrate for the augmented glycolytic activity, tumor cells exhibit an increased expression of facilitated glucose transporters. ${ }^{4}$

A super-family of membrane proteins regulates the transport of glucose in human cells. ${ }^{5}$ These transporters are expressed in a tissue specific manner and are overexpressed in many primary tumors of these tissues.. ${ }^{4}$ GLUT1 is ubiquitously expressed and its overexpression has been studied in primary tumors of many tissues including lung, ${ }^{6,7}$ breast, ${ }^{8,9}$ colon, ${ }^{10,11}$ and stomach. ${ }^{12,13}$

Even though most studies show an increase in Class I (GLUT1-4) glucose transport facilitators in tumor tissues, some studies suggest that these 
transporters are not significantly increased in some primary tumors. ${ }^{14}$ Increased expression of the newly discovered Class III glucose transporters (GLUT6, $-8,-10$, and -12 ) might account for the increase in substrate for the observed augmented glycolytic activity of these tumors.

GLUT8 expression has been identified in several human tumor libraries of expression sequence tags (ESTs) including breast, neuronal, pancreatic, and colon cancers. ${ }^{15}$ GLUT1 shows differential expression during the various phases of the menstrual cycle, which may make it an important marker for endometrial differentiation. ${ }^{16}$ Wang et $a l^{17}$ have demonstrated overexpression of GLUT1 as a consistent feature of endometrial adenocarcinoma. They also demonstrated GLUT1 to be a potential marker of an existing adenocarcinoma in what otherwise was thought to be precancerous lesion.

The following experiments were conducted to quantify and localize the expression of GLUT1 and GLUT8 in benign endometrium and compare this expression to endometrial cancer. The overexpression of GLUT1 and GLUT8 in endometrial cancer is discussed.

\section{Patients and methods}

\section{Endometrial Tissue Sample Collection and Processing}

After Institutional Review Board approval (IRB \#1200009305), 65 women who underwent hysterectomy from September 2000 to April 2002, for any indication, were included in this study. Tissue samples were obtained by a pathologist and snap frozen in liquid nitrogen. For patients without evidence of cancer, the uterus was opened and a portion of endometrium only was taken from the uterine fundus. For patients with endometrial cancer, after a frozen section was obtained and the diagnosis confirmed, a sample of tumor was obtained from an area adjacent to the frozen section site. Tumor tissue was formalin-fixed and paraffinembedded for histopathology as well as GLUT1 and GLUT8 immunofluoresence. All tumors were stained for estrogen receptor (ER) and progesterone receptor $(\mathrm{PR})$ by the gynecologic pathology division. Medical records were reviewed for age, race, and parity, past medical history, past cancer history, past tobacco and alcohol use.

\section{Antibodies}

An antibody to the carboxy-terminus of the GLUT1 glucose transporter was generously provided by Anthony L McCall, MD, PhD, and used for immunoblot analysis. ${ }^{18,19} \mathrm{~A}$ rabbit polyclonal antibody to a 13 amino-acid peptide sequence corresponding to the carboxy-terminus of human GLUT1 was used for immunolocalization of GLUT1 (Alpha Diagnostic International, San Antonio, TX, USA).
A rabbit polyclonal antibody to the carboxyterminus of GLUT8 (LEQITAHFEGR) was used for immunoblot and immunofluoresence localization of GLUT8, as previously described. ${ }^{20-22}$

\section{Protein Purification and Immunoblot Analysis}

Approximately $100 \mu \mathrm{g}$ of sample tissue was homogenized on ice using a Polytron homogenizer in 'Buffer A' (250 mM sucrose, $20 \mathrm{mM}$ HEPES, $1 \mathrm{mM}$ EDTA, $1 \mathrm{mM}$ DTT, $0.5 \mu \mathrm{l} / \mathrm{ml}$ leupeptin, $0.5 \mu \mathrm{l} / \mathrm{ml}$ pepastatin, and $0.67 \mu \mathrm{l} / \mathrm{ml}$ PMSF (0.2 M stock)). Insoluble material was removed by centrifugation at $4{ }^{\circ} \mathrm{C}$ for $10 \mathrm{~min}$ at 4000 r.p.m. with removal of the supernatant, which was subjected to a second centrifugation at $4^{\circ} \mathrm{C}$ for $10 \mathrm{~min}$ at 9000 r.p.m. The supernatants were subjected to a final centrifugation at $4{ }^{\circ} \mathrm{C}$ at 90000 r.p.m. Total membrane pellets were resuspended in 'Buffer B' (2\% Thesit in PBS, $1 \mu \mathrm{l} / \mathrm{ml}$ leupeptin, $1 \mu \mathrm{l} / \mathrm{ml}$ pepastatin, and $0.67 \mu \mathrm{l} / \mathrm{ml} \mathrm{PMSF}$ (0.2 M stock)). Protein concentrations were determined using BCA protein assay reagents (Pierce Biotechnology Inc., Rockford, IL, USA). Approximately $70 \mu \mathrm{g}$ of protein was run on a $10 \%$ SDS-PAGE gel, and protein was transferred to a nitrocellulose membrane at $4{ }^{\circ} \mathrm{C}$ for $3 \mathrm{~h}$ at $500 \mathrm{mAmp}$. Ponceau $\mathrm{S}$ stain was used to confirm transfer and equal loading of specimens. Membranes were blocked for $1 \mathrm{~h}$ using Tris-buffered saline (TBS) containing 5\% nonfat dry milk in $2 \times$ TBS. After washing the membranes in $1 \times$ TBS, membranes were incubated at room temperature for $1 \mathrm{~h}$ with GLUT8 antibody (1:250) in TBS containing 3\% nonfat dry milk. Membranes were washed five times for 5 min each with Solution I $(2 \times$ TBS, $1 \mathrm{mM}$ EDTA, Triton X-100 $(0.2 \%)) \times 3$, Solution II (Urea, Glycine, Triton X-100 $(1 \%)) \times 1$, Solution $I \times 1$, then incubated with a horseradishperoxidase-conjugated secondary goat anti-rabbit IgG (Pierce Biotechnology Inc., Rockford, IL, USA) (1:50000) at room temperature for $1 \mathrm{~h}$ in TBS containing $1 \%$ nonfat dry milk. Membranes were washed for a total of six times $(5 \mathrm{~min}$ in Solution I $3 \times$, Solution II $1 \times$, Solution I $1 \times$, and $\mathrm{ddH}_{2} \mathrm{O}$ $(\times)$. Detection of antigen bound antibody was carried out with Enhanced Chemiluminence Reagents (Amersham Pharmacia Biotech, Arlington Heights, IL, USA). Membranes were exposed to XRay film, which were then quantified using scanning laser densitometry and NIH Image ${ }^{\circledR}$ software. Following the above procedure, the membranes were washed in $1 \times$ TBS and re-blocked with the $5 \%$ blocking solution. After blocking, the membranes were incubated with an antibody to GLUT1 (1:3000) in TBS containing 3\% nonfat dry milk. The remainder of the protocol was as described above.

\section{Immunofluoresence}

Five representative paraffin embedded specimens from each category were examined $(n=25)$. Immunoflouresence microscopy was performed on $2 \mu \mathrm{m}$ 
sections. Slides were incubated at $60^{\circ} \mathrm{C}$ for $1 \mathrm{~h}$, then deparaffinized using serial dilutions of xylene and rehydrated using serial dilutions of ethanol. Epitope retrieval was performed in a citrate buffer $(0.1 \mathrm{M}$ citric acid, $0.1 \mathrm{M}$ sodium citrate) at $95-98^{\circ} \mathrm{C}$ for $20 \mathrm{~min}$. After the sides were allowed to cool, they were blocked with $1 \%$ bovine serum albumin (BSA) in TBST containing 5\% normal goat serum (Pierce Biotechnology Inc., Rockford, IL,USA) for $15 \mathrm{~min}$ at room temperature. Affinity-purified GLUT8 antibody was applied at a dilution of 1:500 and incubated in a humid tray overnight at $4^{\circ} \mathrm{C}$. Cy3 goat anti-rabbit secondary antibody (Jackson Immunoresearch, West Grove, PA, USA) was applied at a dilution of 1:400, covered, and incubated for $1 \mathrm{~h}$ at room temperature. Slides were washed in TBST three times for $5 \mathrm{~min}$ each. Coverslips were mounted with antifade mounting media (Molecular Probes Inc., Eugene, OR, USA), covered, and allowed to polymerize. GLUT8 expression was considered positive if cytoplasmic or membrane staining was present in glandular epithelium. Staining of myometrial smooth muscle and vessel endothelium served as internal controls. Staining of specimens with serum IgG (1:500) and peptide-competed antibody (1:500) served as negative controls to confirm the specificity of immunostaining.

\section{Statistical Analysis}

Densitometric data was analyzed using KruskalWallis testing on SAS v8.2 software. Differences were considered significant at $P>0.05$.

\section{Results}

\section{Patient Demographics}

We examined endometrial samples from 65 women who had undergone hysterectomy and categorized them based on histopathology into benign (atrophic endometrium $(n=13)$, proliferative endometrium $(n=13)$, secretory endometrium $(n=12))$, and malignant (well-differentiated endometrial adenocarcinoma $(n=15)$, poorly differentiated endometrial adenocarcinoma $(n=7)$, and uterine papillary serous carcinoma (UPSC) $(n=5)$ ) tissue types (Table 1 ). There was no apparent difference in median age between patients with atrophic endometrium and those patients in the endometrial cancer groups. There were more hypertensive and diabetic patients in the cancer groups compared to the benign groups. The well-differentiated tumors were all stage I (confined to the uterus) tumors while in the poorly differentiated tumors, $50 \%$ were a more advanced stage, with extra-uterine disease. The BMI of patients with poorly differentiated tumors was higher than expected and previously reported. ${ }^{23,24}$ The majority of well-differentiated tumors were ER and PR positive, while the UPSC tumors were all ER and PR negative. The poorly differentiated tumors demonstrated higher levels of ER and PR staining compared to that reported in the literature. ${ }^{25}$

\section{GLUT1 and GLUT8 Protein Expression in Benign Endometrium and Endometrial Adenocarcinoma}

GLUT8 protein expression was present in all 65 patients. A $35.4 \mathrm{kDa}$ immunoreactive species representative of GLUT8 was demonstrated in normal endometrium and endometrial adenocarcinoma (Figure 1). Quantitative densitometric analysis revealed GLUT8 to be upregulated in all endometrial tissue types as compared to atrophic endometrium. GLUT8 was upregulated 2.54-fold in well-differentiated endometrial adenocarcinoma, 2.92-fold in poorly differentiated endometrial adenocarcinoma, and 3.13-fold in UPSC when compared to atrophic endometrium $(64.72 \pm 8.8,74.22 \pm 15,79.09 \pm 8.9$ vs

Table 1 Patient demographics

\begin{tabular}{|c|c|c|c|c|c|c|}
\hline & $\begin{array}{c}\text { Atrophic } \\
\text { endometrium } \\
(\mathrm{n}=13)\end{array}$ & $\begin{array}{l}\text { Proliferative } \\
\text { endometrium } \\
\quad(\mathrm{n}=13)\end{array}$ & $\begin{array}{c}\text { Secretory } \\
\text { endometrium } \\
(\mathrm{n}=12)\end{array}$ & $\begin{array}{l}\text { Well-differentiated } \\
\text { adenocarcinoma } \\
\qquad(\mathrm{n}=15)\end{array}$ & $\begin{array}{l}\text { Poorly differentiated } \\
\text { adenocarcinoma } \\
\qquad(\mathrm{n}=7)\end{array}$ & $U P S C(\mathrm{n}=5)$ \\
\hline Diabetics & $0(0)$ & $0(0)$ & $0(0)$ & $3(20 \%)$ & $3(43 \%)$ & $3(60 \%)$ \\
\hline $\mathrm{HTN}$ & 4 & 1 & 1 & 8 & 4 & 1 \\
\hline \multicolumn{7}{|l|}{ Stage } \\
\hline I & NA & NA & NA & 15 & 3 & 1 \\
\hline II & NA & NA & NA & 0 & 3 & 1 \\
\hline III & NA & NA & NA & 0 & 1 & 2 \\
\hline IV & NA & NA & NA & 0 & 0 & 1 \\
\hline Median BMI (range) & $22(17-37.7)$ & $28.9(22.5-42.2)$ & $27.8(21.4-34.4)$ & $30.6(22.5-59.7)$ & $34.8(24-42.5)$ & $27(19.5-28)$ \\
\hline Mean \% ER & NA & NA & NA & $6 \%$ & $59 \%$ & $0 \%$ \\
\hline Mean \% PR & NA & NA & NA & $74 \%$ & $62 \%$ & $2 \%$ \\
\hline
\end{tabular}



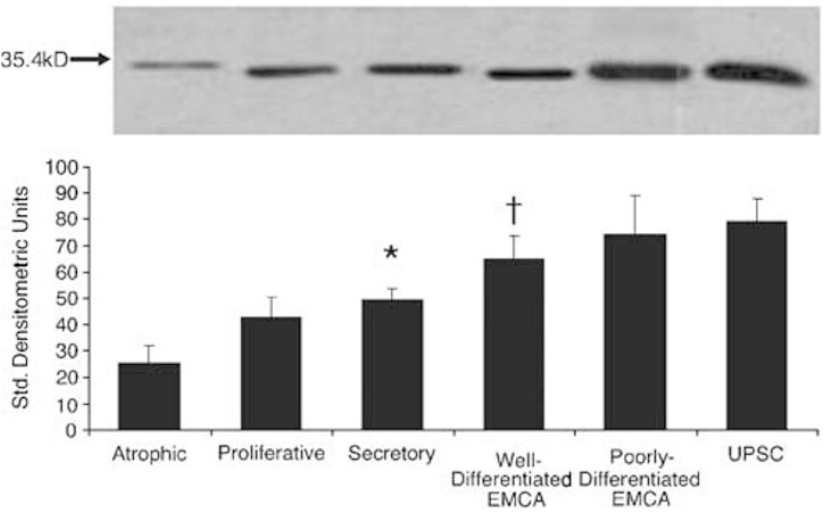

Figure 1 Expression of GLUT8 in endometrium and endometrial adenocarcinoma specimens. Immunoblot analysis was used to examine the expression of GLUT8 in the endometrial tissue samples. A $35.4 \mathrm{kDa}$ immunoreactive species representative of GLUT8 was demonstrated in normal endometrium and endometrial adenocarcinoma. Quantitative densitometric analysis revealed GLUT8 to be upregulated in all tissues when compared to atrophic endometrium ( $\left.{ }^{*} P<0.05,{ }^{\dagger} P<0.001\right)$. $\mathrm{kDa}=$ kilodalton; $\mathrm{EMCA}=$ endometrial adenocarcinoma; $\mathrm{UPSC}=$ uterine papillary serous carcinoma.

$25.41 \pm 6.2$, respectively, $P<0.001$ ). There was a trend toward increased GLUT8 expression in poorly differentiated endometrial adenocarcinoma and UPSC when compared to well-differentiated endometrial adenocarcinoma; however, this was not significant $(P=0.43$ and 0.29 , respectively).

A total of 47 samples were able to be evaluated for GLUT1 protein expression (atrophic endometrium $(n=4)$, proliferative endometrium $(n=12)$, secretory endometrium $(n=10)$, well-differentiated endometrial adenocarcinoma $(n=9)$, poorly differentiated endometrial adenocarcinoma $(n=7)$, UPSC $(n=5))$. A $44 \mathrm{kDa}$ immunoreactive heterogeneously glycosylated species representative of GLUT1 was demonstrated in benign endometrium and endometrial adenocarcinoma (Figure 2). There is a step-wise increase in GLUT1 as the tumor type becomes more poorly differentiated. GLUT1 has a twofold increased expression in UPSC tumors compared to well-differentiated adenocarcinoma $(116 \pm 20$ vs $62 \pm 38, P<0.002)$. There is a $50 \%$ increase in expression when comparing UPSC tumors to poorly differentiated adenocarcinoma $(116 \pm 20$ vs $83 \pm 61$, $P<0.06)$. Age, diabetes, blood glucose, ER percent and PR percent are correlated with histopathologic type for both GLUT1 and GLUT8. No other covariate (singular or multivariate) is significant in the model after adjustment for type.

\section{GLUT1 and GLUT8 Immunofluoresence in Benign Endometrium and Endometrial Adenocarcinoma}

Immunolocalization of GLUT1 and GLUT8 in representative samples of the various tissue types ( $n=5$ from each subtype) was performed. Apical localization of GLUT8 was detected in endometrial



Figure 2 Expression of GLUT1 in endometrium and endometrial adenocarcinoma specimens. Immunoblot analysis was used to examine the expression of GLUT1 in the endometrial tissue samples. A $44 \mathrm{kDa}$ immunoreactive heterogeneously glycosylated species representative of GLUT1 was demonstrated in benign endometrium and endometrial adenocarcinoma. There is a stepwise increase in GLUT1 as the tumor type becomes less well differentiated. GLUT1 has a twofold increased expression in UPSC tumors compared to well-differentiated adenocarcinoma $\left({ }^{*} P<0.002\right)$. There is a $50 \%$ increase in expression when comparing UPSC tumors to poorly differentiated adenocarcinoma $(P<0.06) . \mathrm{kDa}=$ kilodalton; EMCA $=$ endometrial adenocarcinoma; UPSC $=$ uterine papillary serous carcinoma.

glands of benign tissues. GLUT8 demonstrated diffuse intracellular localization in the cancer subtypes (Figure 3). As with GLUT8, GLUT1 immunofluoresence staining demonstrated glandular apical staining, with minimal cytoplasmic staining in benign tissue types (Figure 4). GLUT1 was also noted to have diffuse cytoplasmic staining in tumor tissue. There was marked staining of GLUT1 and GLUT8 in inflammatory cells as well as red blood cells. GLUT8 staining of tumors demonstrating lymphovascular space invasion (LVI) was also noted. Myometrial staining was minimal and served as an internal control for both GLUT1 and GLUT8. No staining was noted in samples where serum immunoglobulin or peptide-competed antibody was used as the primary antibody.

\section{Discussion}

Approximately 41,200 new cases of endometrial cancer are estimated to be diagnosed in $2006 .{ }^{26}$ Two types of endometrial cancer have been described: estrogen-reponsive and estrogen-independent. The second type of endometrial cancer is a more aggressive tumor and is frequently associated with extra-uterine disease. In our study, the type II poorly differentiated tumors had higher than expected BMI and estrogen receptor expression. This may be more reflective of our obese patient population than of biologic significance. ${ }^{23,24}$

This is the first report of GLUT8 in any type of human cancer of the female reproductive system. 

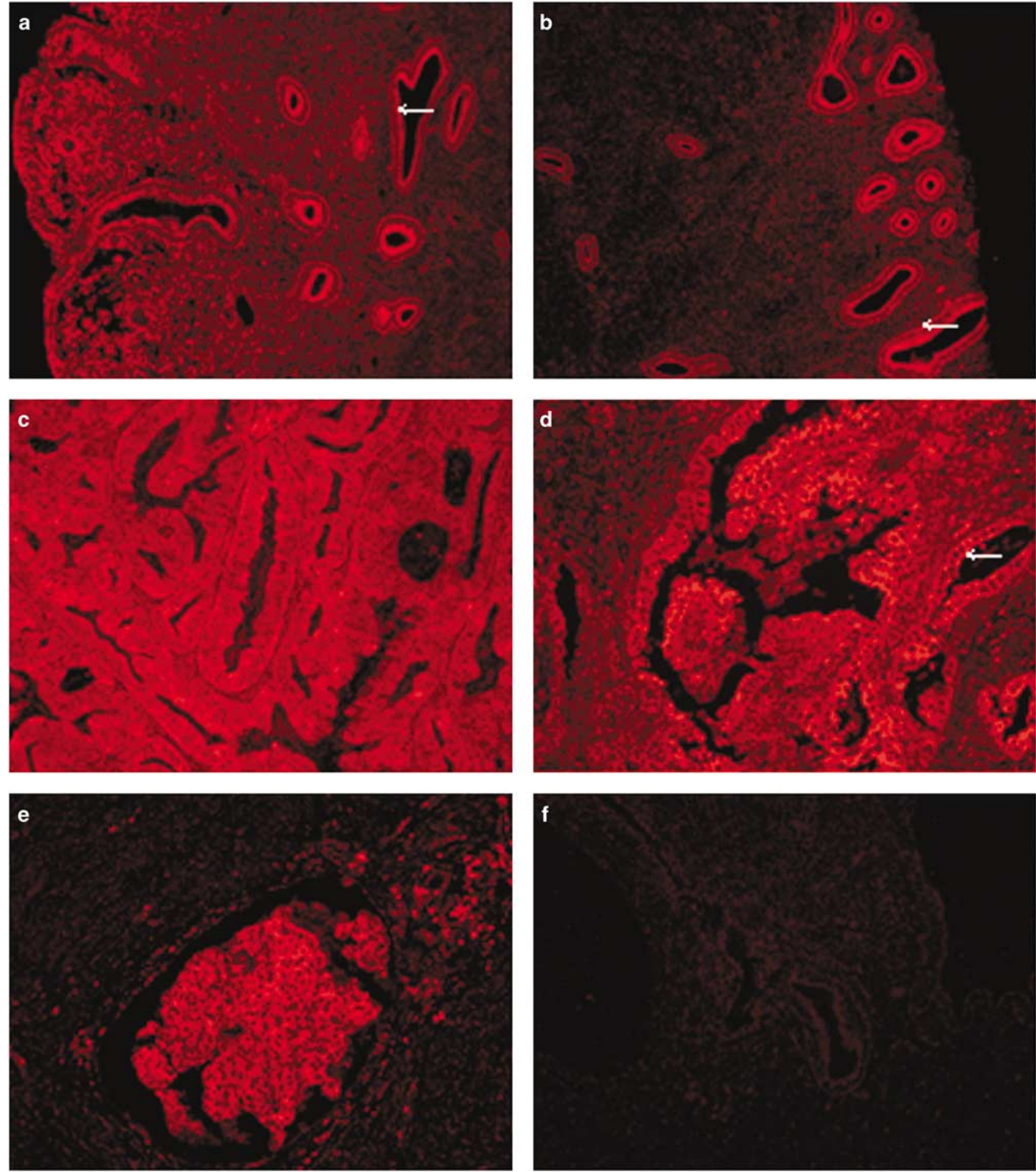

Figure 3 Immunolocalization of GLUT8 in endometrial tissue and endometrial adenocarcinoma. (a, b) Cystic atrophic endometrium and proliferative endometrium, respectively, demonstrating strong apical localization of GLUT8 (white arrows). The minimal myometrial staining served as an internal control. (c) Well-differentiated endometrial adenocarcinoma demonstrating diffuse cytoplasmic localization of GLUT8. (d) Uterine papillary serous carcinoma with diffuse intracellular localization of GLUT8. A benign endometrial gland maintains its apical localization even in the malignant tissue (white arrow). (e) GLUT8 localization is noted in an area of lymphovascular space invasion. (f) Negative-control for immunofluorescence using serum immunoglobulin only.

Our experiments represent the first prospective study to characterize the expression of GLUT1 and GLUT8 in human endometrial tissue. Because other
GLUTs were demonstrated to have expression in endometrium, ${ }^{27-30}$ and because GLUT8 appeared to be hormonally regulated,,$^{27,30,31}$ we hypothesized 

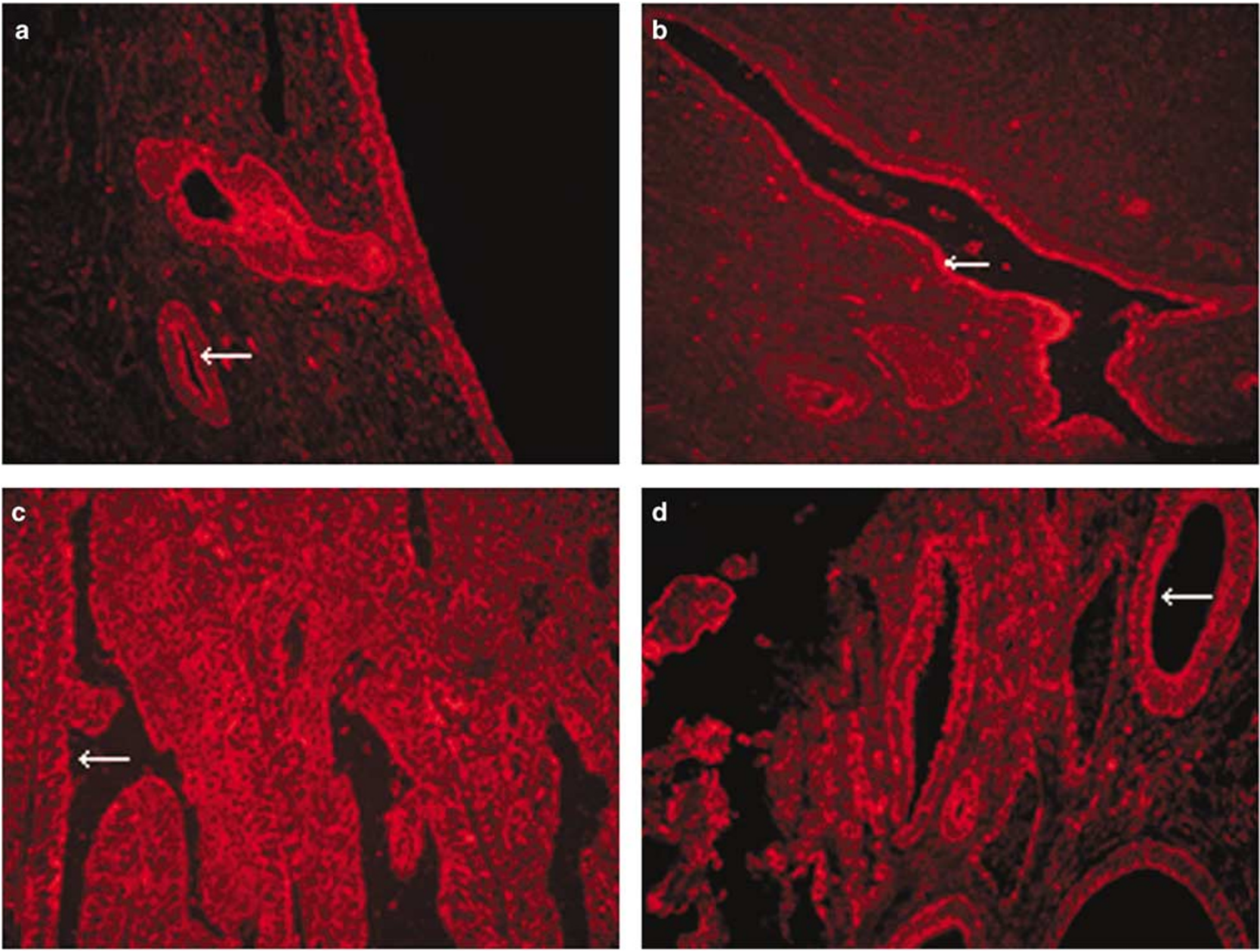

Figure 4 Immunolocalization of GLUT1 in endometrial tissue and endometrial adenocarcinoma. (a, b) Cystic atrophic endometrium demonstrating constitutive expression and strong apical localization of GLUT1 (white arrow). (c) Well-differentiated endometrial adenocarcinoma demonstrating diffuse cytoplasmic localization of GLUT1. (d) Uterine papillary serous carcinoma with diffuse intracellular localization of GLUT1. Benign endometrial glands maintain apical localization of GLUT1 even in the malignant tissue (white arrows).

that GLUT1 and GLUT8 would be overexpressed in endometrial cancer compared to benign endometrial tissue, controlled for menopausal status. As with the upregulation of glucose transporters in other cancers, the upregulation of GLUT1 and GLUT8 may identify poorly differentiated, thus more aggressive endometrial tumors.

Expression of certain glucose transporters has been correlated with tumor aggressiveness. ${ }^{1-3}$ Recently, a study examined GLUT1 immunohistochemical staining in normal endometrium and endometrial carcinoma. ${ }^{17}$ This study demonstrated no staining in normal endometrium and membranous staining in glandular epithelium in atypical endometrial hyperplasia and endometrial adenocarcinoma. This staining was subjectively scored and only one-third of the tumors showed very extensive staining for GLUT1 expression. As, the poorly differentiated tumors were categorized together, aggressive histopathologic subtypes could not be independently evaluated to examine GLUT1 expression.
The prognostic significance of GLUT1has been studied in colorectal cancer. ${ }^{10}$ There was a 2.4 -fold increased risk of death in patients with tumors in which greater than $50 \%$ of the cells demonstrated GLUT1 immunostaining as compared to those with $<50 \%$ of the cells immunostaining positive for GLUT1. The authors reported a correlation of GLUT1 immunostaining was associated with an increased risk of metastases In colorectal cancer, tumors with $>50 \%$ immunostaining of GLUT1 Younes et $a l^{11}$ reported an increase risk of lymph nodal metastases. Other investigators have reported a correlation between breast cancer grade and GLUT1 expression. ${ }^{9,32,33}$ However, only $42-58 \%$ of tumors expressed GLUT1. These types of analyses are limited to qualitative statements, which cannot be quantified and may miss small but significant increase in expression.

Our data demonstrate GLUT1 protein expression in both benign and malignant tissue types. This is contrary to the data presented in immunohisto- 
chemical studies where the normal tissue did not express GLUT1 compared to the corresponding tumor type. ${ }^{10,17}$ Our immunolocalization also confirms the presence of GLUT1 in benign endometrial tissues. It may be that the antibody used in prior studies was not sensitive enough to detect lower levels of protein expression. There also appears to be a step-wise increase in GLUT1 as the tumor type becomes de-differentiated, correlating with the increased need for glucose in tumor cells. Because of the small number of patients, and the inclusion of all stages of disease, we are unable to correlate GLUT1 protein expression with the risk of metastasis, prognosis or stage.

Immunoblot analysis shows that GLUT8 protein expression is significantly upregulated in all cancer types compared to atrophic endometrium (Figure 1). Recently, von Wolff et $a l^{30}$ analyzed endometrial tissue for GLUT8 by northern blot analysis and found no GLUT8 mRNA expression. The reason(s) for these differing results is unclear. However, their study was carried out on younger women (22-39 years old), as compared to our patient population (Table 1). Our data shows a trend toward increased GLUT8 expression with increased tumor grade. The demonstration of GLUT8 in endometrial cancers suggests a role for GLUT8 in providing glucose to pathways that sustain uncontrolled cellular proliferation. It is possible that GLUT8 is not involved in glucose transport in benign endometrial epithelium, but is activated upon malignant transformation. This has been described in other tumor types and glucose transporters. Rogers et al reported low levels of Class III GLUT12 protein localization in normal human breast tissue with marked overexpression in invasive breast tumors. ${ }^{34}$ However, they did not notice a difference in GLUT12 immunolocalization. ${ }^{33}$ They hypothesize that proteins required for fetal development, which have a high glucose requirement, can be reactivated in cancer cells which also require high amounts of substrate. Further studies with regard to glucose uptake kinetics using GLUT1 and GLUT8 in endometrial cell culture are warranted.

Although the exact mechanism is unknown, there are various factors that could regulate the translocation or re-distribution of these transporters in endometrial cells. GLUT8 contains a di-leucine motif which is important for intracellular localization. Mutation of the di-leucine motifs caused localization of GLUT8 to the plasma membrane. ${ }^{35}$ Pinto et $a l^{36}$ demonstrated that GLUT8 redistibution was essential for cell survival. By inhibiting the IGF-1R receptor with antisense oligonucleotides, they effectively inhibited GLUT8 translocation to the cytoplasm and blastocyst survival. A second potential mechanism is the phosphorylation of GLUT4 at Ser-488, which promotes intracellular sequestration of GLUT4. ${ }^{37}$ As GLUT8 has many structural similarities to GLUT4, it is possible that this phosphorylation event could occur on GLUT8 during malignant transformation of endometrial cells.
This is the first study to demonstrate GLUT1 and GLUT8 expression in human endometrial tissue and endometrial adenocarcinoma. We were also able to use fresh specimens to allow for quantitative immunoblot analysis. We demonstrate significant increases of these two glucose transporters in tumor tissue, and an increase in expression as tumor grade increases and histopathology worsens. The immunoblot data combined with the immunofluoresence suggest that upregulation of GLUT1 and GLUT8 may play a role in the invasiveness of endometrial carcinoma. Studies designed to determine the effect of inhibition of one or both of these glucose transporters on tumor growth and invasiveness may be of therapeutic value.

\section{Acknowledgements}

Generous support for these studies was obtained from the National Institutes of Health (DK47425 and HL58119 to MJC) and the American Diabetes Association (to MJC) and the HERA Foundation (to CDR).

\section{References}

1 Warburg O. The Metabolism of Tumors. Arnold Constable: London, 1930.

2 Aisenberg AC. The Glycolysis and Respiation of Tumors. Academic Press: London, 1961.

3 Burk DA. Colloquial consideration of the Pasteur and neo-Pasteur effects. Cold Spring Harbor Sympos Quant Biol 1939;7:420-459.

4 Medina RA, Owen GI. Glucose transporters: expression, regulation and cancer. Biol Res 2002;35:9-26.

5 Joost HG, Bell GI, Best JD, et al. Nomenclature of the GLUT/SLC2A family of sugar/polyol transport facilitators. Am J Physiol Endocrinol Metab 2002;282: E974-E976.

6 Kurata T, Oguri T, Isobe T, et al. Differential expression of facilitative glucose transporter (GLUT) genes in primary lung cancers and their liver metastases. Jpn J Cancer Res 1999;90:1238-1243.

7 Younes M, Brown RW, Stephenson M, et al. Overexpression of Glut1 and Glut3 in stage I nonsmall cell lung carcinoma is associated with poor survival. Cancer 1997;80:1046-1051.

8 Brown RS, Wahl RL. Overexpression of Glut-1 glucose transporter in human breast cancer. An immunohistochemical study. Cancer 1993;72:2979-2985.

9 Younes M, Brown RW, Mody DR, et al. GLUT1 expression in human breast carcinoma: correlation with known prognostic markers. Anticancer Res 1995; 15:2895-2898.

10 Haber RS, Rathan A, Weiser KR, et al. GLUT1 glucose transporter expression in colorectal carcinoma: a marker for poor prognosis. Cancer 1998;83:34-40.

11 Younes M, Lechago LV, Lechago J. Overexpression of the human erythrocyte glucose transporter occurs as a late event in human colorectal carcinogenesis and is associated with an increased incidence of lymph node metastases. Clin Cancer Res 1996;2:1151-1154. 
12 Kawamura T, Kusakabe T, Sugino T, et al. Expression of glucose transporter-1 in human gastric carcinoma: association with tumor aggressiveness, metastasis, and patient survival. Cancer 2001;92:634-641.

13 Noguchi Y, Marat D, Saito A, et al. Expression of facilitative glucose transporters in gastric tumors. Hepatogastroenterology 1999;46:2683-2689.

14 Musholt TJ, Musholt PB, Dehdashti F, et al. Evaluation of fluorodeoxyglucose-positron emission tomographic scanning and its association with glucose transporter expression in medullary thyroid carcinoma and pheochromocytoma: a clinical and molecular study. Surgery 1997;122:1049-1060; discussion 1060-1061.

15 Doege H, Schurmann A, Bahrenberg G, et al. GLUT8, a novel member of the sugar transport facilitator family with glucose transport activity. J Biol Chem 2000;275: 16275-16280.

16 Strowitzki T, Capp E, von Wolff M, et al. Expression of glucose transporter 1 in human endometrial and decidual tissue. Gynecol Endocrinol 2001;15:219-224.

17 Wang BY, Kalir T, Sabo E, et al. Immunohistochemical staining of GLUT1 in benign, hyperplastic, and malignant endometrial epithelia. Cancer 2000;88: 2774-2781.

18 McCall AL, Van Bueren AM, Nipper V, et al. Forebrain ischemia increases GLUT1 protein in brain microvessels and parenchyma. J Cereb Blood Flow Metab 1996;16:69-76.

19 Van Bueren AM, Moholt-Siebert M, Begley DE, et al. An immunization method for generation of high affinity antisera against glucose transporters useful in immunohistochemistry. Biochem Biophys Res Commun 1993;197:1492-1498.

20 Moadel RM, Weldon RH, Katz EB, et al. Positherapy: targeted nuclear therapy of breast cancer with $18 \mathrm{~F}-2$ deoxy-2-fluoro-D-glucose. Cancer Res 2005;65: 698-702.

21 Gorovits N, Cui L, Busik JV, et al. Regulation of hepatic GLUT8 expression in normal and diabetic models. Endocrinology 2003;144:1703-1711.

22 Reagan LP, Rosell DR, Alves SE, et al. GLUT8 glucose transporter is localized to excitatory and inhibitory neurons in the rat hippocampus. Brain Res 2002;932: 129-134.

23 Lax SF, Pizer ES, Ronnett BM, et al. Clear cell carcinoma of the endometrium is characterized by a distinctive profile of p53, Ki-67, estrogen, and progesterone receptor expression. Hum Pathol 1998;29: 551-558.

24 Lax SF, Pizer ES, Ronnett BM, et al. Comparison of estrogen and progesterone receptor, Ki-67, and p53 immunoreactivity in uterine endometrioid carcinoma and endometrioid carcinoma with squamous, muci- nous, secretory, and ciliated cell differentiation. Hum Pathol 1998;29:924-931.

25 Fukuda K, Mori M, Uchiyama M, et al. Prognostic significance of progesterone receptor immunohistochemistry in endometrial carcinoma. Gynecol Oncol 1998;69:220-225.

26 American Cancer Society Facts and Figures. American Cancer Society: Atlanta, Georgia, 2006.

27 Korgun ET, Demir R, Hammer A, et al. Glucose transporter expression in rat embryo and uterus during decidualization, implantation, and early postimplantation. Biol Reprod 2001;65:1364-1370.

28 Mioni R, Chiarelli S, Xamin N, et al. Evidence for the presence of glucose transporter 4 in the endometrium and its regulation in polycystic ovary syndrome patients. J Clin Endocrinol Metab 2004;89:4089-4096.

29 Sato M, Nakamura Y, Sogawa T, et al. Immunolocalization of glucose transporter 1 and 3 in the placenta: application to cytodiagnosis of Papanicolaou smear. Diagn Cytopathol 2002;26:373-379.

30 von Wolff $\mathrm{M}$, Ursel S, Hahn U, et al. Glucose transporter proteins (GLUT) in human endometrium: expression, regulation, and function throughout the menstrual cycle and in early pregnancy. J Clin Endocrinol Metab 2003;88:3885-3892.

31 Welch RD, Gorski J. Regulation of glucose transporters by estradiol in the immature rat uterus. Endocrinology 1999;140:3602-3608.

32 Alo PL, Visca P, Botti C, et al. Immunohistochemical expression of human erythrocyte glucose transporter and fatty acid synthase in infiltrating breast carcinomas and adjacent typical/atypical hyperplastic or normal breast tissue. Am J Clin Pathol 2001;116: 129-134.

33 Macheda ML, Williams ED, Best J, et al. Expression and localisation of GLUT1 and GLUT12 glucose transporters in the pregnant and lactating rat mammary gland. Cell Tissue Res 2003;311:91-97.

34 Rogers S, Docherty SE, Slavin JL, et al. Differential expression of GLUT12 in breast cancer and normal breast tissue. Cancer Lett 2003;193:225-233.

35 Ibberson M, Uldr M, Thorens B. GLUTX1, a novel mammalian glucose transporter expressed in the central nervous system and insulin-sensitive tissues. J Biol Chem 2000;275:4607-4612.

36 Pinto AB, Carayannopoulos $\mathrm{MO}$, Hoehn $\mathrm{A}$, et al. Glucose transporter 8 expression and translocation are critical for murine blastocyst survival. Biol Reprod 2002;66:1729-1733.

37 Lawrence Jr JC, Hiken JF, James DE. Stimulation of glucose transport and glucose transporter phosphorylation by okadaic acid in rat adipocytes. J Biol Chem 1990;265:19768-19776. 